\title{
Phylogenomics reveals a complex evolutionary history of lobed-leaf white oaks in Western North America
}

\begin{tabular}{|r|l|}
\hline Journal: & Genome \\
\hline Manuscript ID & gen-2016-0206.R1 \\
\hline Manuscript Type: & Article \\
\hline Date Submitted by the Author: & $20-$ Mar-2017 \\
\hline Complete List of Authors: & $\begin{array}{l}\text { McVay, John; Duke University Department of Biology } \\
\text { Hauser, Duncan; Duke University Department of Biology } \\
\text { HIPP, ANDREW; The Morton Arboretum, ; The Field Museum, Botany } \\
\text { Manos, Paul; Duke University Department of Biology }\end{array}$ \\
\hline $\begin{array}{r}\text { Is the invited manuscript for } \\
\text { consideration in a Special } \\
\text { Issue? : }\end{array}$ & Evolution of Tree Diversity \\
\hline Keyword: & Quercus, RADseq, hybridization, introgression \\
\hline &
\end{tabular}

SCHOLARONE ${ }^{\text {m }}$

Manuscripts 
Phylogenomics reveals a complex evolutionary history of lobed-leaf white oaks in Western North America
Authors
John D McVay ${ }^{1}$
Duncan Hauser ${ }^{1}$
Andrew L. Hipp ${ }^{2}$
Paul Manos ${ }^{1}$ 


\section{ABSTRACT}

Quercus (oak) species hybridize in complex patterns that have yet to be fully explored with phylogenomic data. Analyses to date have recovered reasonable divergent patterns, suggesting that the impact of introgression may not always be obvious in inferred oak phylogenies. We explore this phenomenon using RADseq data for 136 samples representing 54 oak species by conducting phylogenetic analyses designed to distinguish signals of lineage diversification and hybridization, focusing on the lobed-leaf species Quercus gambelii, Q. lobata, and Q. garryana in the context of a broad sampling of allied white oaks (Quercus section Quercus), and particularly the Midwestern $Q$. macrocarpa. We demonstrate that historical introgressive hybridization between once sympatric species affects phylogeny estimation. Historical range expansion during periods of favorable climate likely explains our observations; analyses support genetic exchange between ancestral populations of $Q$. gambelii and Q. macrocarpa. We conclude that the genomic consequences of introgression caused the attraction of distant lineages in phylogenetic tree space, and that introgressive and divergent signals can be disentangled to produce a robust estimate of the phylogenetic history of the species.

Keywords: Quercus, RADseq, hybridization, introgression 


\section{INTRODUCTION}

The advent of second generation DNA sequencing technologies has lent unprecedented power to genetic and genomic analyses across life science disciplines. As phylogenetic tools have been developed to accommodate these datasets, patterns of lineage divergence and diversification have emerged that were previously undetectable (e.g., O'Neill et al. 2013; Piednoël et al. 2012; Prum et al. 2015). And though historical hybridization has remained a challenge to model in a phylogenetic framework (Nakhleh 2013), the scale of datasets afforded by these new technologies has allowed for more robust perspectives on the role that introgression may play in shaping the tree of life (Arnold 2015; Bapteste et al. 2013). Oaks, having long been suspected to hybridize widely (and confirmed genetically, in many cases; e.g., Belahbib et al. 2001; Craft et al. 2002; Eaton et al. 2015; Kremer et al. 2002; Zeng et al. 2010), are an ideal system in which to apply these novel approaches to investigating reticulating evolutionary patterns.

Recent studies using nuclear DNA markers suggest that current hybridization will not pose an insurmountable barrier to understanding the shape and timing of the oak phylogeny (Eaton et al. 2015; Hipp 2015; Hipp et al. 2014; Muir et al. 2000; Pearse and Hipp 2009). Moreover, multigene datasets provide evidence for the existence of species boundaries among relatively closely related species occurring in sympatry, even in the face of gene flow (e.g., Cavender-Bares et al. 2015; Craft et al. 2002; Eaton et al. 2015; Gailing and Curtu 2014; Hipp and Weber 2008; Lepais and Bacles 2014; Leroy et al. 2017). However, it is undoubtedly the case from these and related studies that oaks have 
been hybridizing since their inception, and the signature of historical introgression in the oaks may be particularly cryptic, because signals of ancient introgression are effaced by the more obvious signals of contemporary gene flow. Genetic evidence suggests the presence of several former contact zones where only traces of the alleles (Dodd and Afzal-Rafii 2004) or morphology (Maze 1968) of a contributing parental species can been found today. But we lack a phylogenetic perspective on these ancestral hybridization stories. Such a perspective is needed to distinguish contemporary hybridization between modern species from historical gene flow among interior branches of the phylogeny.

The white oaks of North America, represented by more than 50 species and several discrete syngamea that have been noted in the literature (Grant 1981; Hardin 1975), offer a particularly useful system for investigating the interplay between contemporary and historical hybridization in generating the diversity we observe in oaks today. Preliminary phylogenomic data suggest that biogeographic boundaries and differential climatic regions have shaped the evolution of regionally limited clades (Manos 2016). The relationship between eastern and western white oak species is interesting in this regard, particularly the species with lobed leaves (Fig. 1). Lobed-leaf species are concentrated in eastern North America and best exemplified by the most common species, Q. alba. However, the ranges of several other eastern lobed-leaf species extend west into the Dakotas and Texas (e.g. Q. macrocarpa). In western North America, two lobed-leaf species, Q. lobata and Q. garryana, are typical of more mesic California Floristic Province (CFP) habitats. Of long standing interest is Q. gambelii, a shrub to small tree 
common throughout the southern Rocky Mountains, but fragmented in distribution (see Fig. 1). Despite the high degree of leaf and trichome similarity among $Q$. gambelii, $Q$. lobata and Q. garryana (e.g., Nixon and Muller 1997), Q. gambelii has never been classified with other lobed-leaf species (Camus 1936-1954; Muller 1951; Trelease 1924). Quercus gambelii is also known to hybridize with at least 7 species of white oaks in the southwestern US (Howard et al. 1997; Tucker 1963). Given its distribution intermediate between the ranges of eastern and western lobed-leaf clades, the phylogenetic position of Q. gambelii remains an important unsettled question in oak systematics and biogeography.

In this paper, we use genomic data to address the phylogeny of the lobed-leaved white oaks of western North America and to investigate hypotheses of introgressive hybridization. We utilize a reduced-representation genomic sequencing approach, restriction-site associated DNA sequencing (RADseq), combined with phylogenetic analyses that partition the dataset to distinguish primary and secondary phylogenetic signals, reflecting both lineage diversification and hybridization, that have shaped the origins of Quercus gambelii, Q. lobata, Q. garryana and allied species. In the end, we present the first phylogenetic history of the interconnections between western and eastern North American oak clades that today constitute distinct evolutionary lineages.

\section{METHODS}


Sample collection.-We sampled 134 individuals of Quercus representing 53 species of white oak, $Q$. pontica and $Q$. sadleriana, two species from subsection Virentes (all representing $\S$ Quercus), and three species of intermediate oaks (§ Protobalanus), and two individuals of Notholithocarpus densiflorus as an outgroup (Appendix). Within thee North American (NA) white oaks, we sampled individuals from each provisionally named subclade identified in preliminary analyses, including Albae, (Eastern NA), Dumosae (California, USA), Prinoideae (Eastern-Midwestern NA), Stellatae (Eastern NA), and two unnamed groups whose ranges span Southwestern NA and California, and Mexico and Central America. Our sampling was especially rich in the lobed oaks of the West and Southwest United States, including ten Quercus gambelii from populations throughout its range (Fig 1.), five Q. garryana and three Q. lobata (Dumosae) and nine $Q$. macrocarpa (Prinoideae; Fig. 1). DNA was extracted from fresh or frozen leaf tissue using the DNEasy plant mini kit (Qiagen, Hilden, Germany) or a modification of the CTAB method optimized for hardwood trees by Lefort and Douglas (1999; supplemental materials). Restriction site-associated DNA (RAD) library preparations were performed by Floragenex (Portland, OR, USA), using the PstI restriction enzyme, as described previously (Baird et al. 2008; see additional discussion in Hipp et al. 2014). Sequencing was conducted between 2012 and 2016 on an Illumina Genome Analyzer IIx at Floragenex or an Illumina HiSeq 2500 at University of Oregon.

Analysis of RADseq.-We processed raw sequence data in pyRAD 3.066 (Eaton 2014), discarding low quality raw reads with more than four nucleotides with a Phred 33 score below 20. Loci were clustered within (at a minimum copy depth of six) then among 
samples (minimum of four individuals per locus) with a minimum 0.88 sequence similarity threshold.

Phylogeny estimation.-We performed a maximum likelihood analysis with 100 nonparametric bootstraps of the concatenated pyRAD output using RAxML 8.2.9 (Stamatakis 2014), under the GTRCAT approximation of the general time-reversible nucleotide substitution model with rate heterogeneity (GTR+gamma) (Stamatakis 2006). Because concatenated data analysis does not model the processes underlying gene tree discordance, we estimated a coalescent species tree using the SVDquartets method (Chifman and Kubatko 2014, 2015) implemented in PAUP (Swofford 2003; Swofford 2016). We choose this method over other available methods that rely on summary statistics as input (e.g.; Mirarab et al. 2014), as any singular gene tree (estimated from $\sim 85 \mathrm{bp}$ sequence data) is likely to be a poor estimate of the underlying genealogy. We performed an exhaustive quartet analysis (i.e., all possible quartets that include a representative of four species were sampled) under the species tree model and performed 100 bootstrap replicates to assess support across the data of the point estimate.

Rank of relatedness based on summed evolutionary distance.- The topology observed in a concatenated phylogenetic analysis may be the product of a single underlying phylogenetic signal; alternatively, when conflicting signal is present, particularly due to introgression, affected lineages may be placed in a position intermediate to their expected placement were no introgression to have occurred (McDade 1992). This result may be particularly problematic when interrogating large datasets, as bootstrap support may be 
strong despite the presence of phylogenetically conflicting signal (Phillips et al. 2004). Therefore, we interrogated the data set on a locus-by-locus, sample-by-sample basis, to assess several points of genealogical discordance among loci. For each individual in the dataset we ranked relatedness to all other individuals in the dataset based on the sum of evolutionary distance estimated from each locus. For each locus, we produced a pairwise distance matrix of HKY-modeled (Hasegawa et al. 1985) neighbor joining distances calculated in PAUP. Then we sorted the distances numerically for each individual. All individuals that exhibited the shortest pairwise distance to the targeted individual were awarded the minimum evolution score of the locus; individuals not meeting this criterion were awarded a score of zero. These scores were then summed for each non-target individual across all loci, scaled by the number of loci each shared with the target individual, then ranked; here we consider the highest scoring individuals considered as being most closely related to the targeted individual. In a purely divergent species tree (i.e., with a single underlying phylogenetic signal), our expectations are that ranks would most closely reflect the branching order of the phylogenetic estimate. To narrow the focus of the analysis, we chose one individual each for $Q$. gambelii, Q. lobata, and $Q$. macrocarpa, and calculated the rankings for all other individuals in the dataset, paying particular attention to the rankings of $Q$. macrocarpa samples in relation to the $Q$. gambelii and Q. lobata samples, and the rankings of the $Q$. gambelii samples in relation to the $Q$. macrocarpa sample. As a null, we observed the rankings of $Q$. michauxii (an Eastern NA oak not in contact, nor suspected to interact with any of the western lobed oaks) specimens to the $Q$. macrocarpa individual. 
Deviations from expected rankings may be caused by gene tree-species tree conflict due to incomplete lineage sorting (ILS) rather than, or in addition to introgression. To assess how these rankings compare to our expectations in the presence of varying degrees of incomplete lineage sorting (ILS), we simulated and analyzed datasets based on the total evidence concatenated estimate with branch lengths modified to simulate three coalescent depths: $1,2.5$, and $10 \mathrm{~N}$-generations, representing differing degrees of expected discordance among gene trees. We simulated 500 datasets at each depth; for each simulated depth, we employed Mesquite (Maddison and Maddison 2011) to simulate 1e5 coalescent gene trees contained within the concatenated estimate with branch lengths modified to the desired three depth. Then, for each simulation replicate, we simulated sequence data on a randomly chosen simulated gene tree, with taxon sampling drawn randomly from the subset of loci in the data in which one or more of the three targeted individuals were represented. We drew from the distribution of taxon sampling for the real dataset to simulate both the degree and non-random nature of missing data. We used seq-gen (Rambaut and Grassly 1997) to simulate 85-basepair clusters for each with substitution rate (tree length) for each cluster drawn from a uniform distribution (0.0010.02). Each simulated dataset was then analyzed in the manner described for the real dataset. To assess significance of the observed rankings, we calculated a test statistic as the arithmetic mean of rank of a targeted taxon (e.g., the mean rank of relatedness of all Quercus macrocarpa samples with respect to the Q. gambelii sample); this value was compared to a distribution of mean ranks of the same individuals across all simulated datasets for each depth. We were interested in individuals more closely related to the queried individuals, significance was assessed as a one-tailed test, where a p-value is the 
proportion of simulated mean ranks that were higher than the observed value, divided by the number of simulations (500).

Because inclusion of hybrid individuals can have incompletely predictable effects on phylogenetic inferences across the tree, we sought to identify individuals of $Q$. gambelii, Q. lobata and Q. macrocarpa that were of potential hybrid ancestry. The 22 samples of these three species were re-clustered via pyRAD, then we analyzed all 22 samples using the admixture model implemented in Structure version 2.3.4 (Pritchard et al. 2000), as has been done in other interspecific oak studies (Antonecchia et al. 2015; Eaton et al. 2015; Lind and Gailing 2013). Two datasets were created. The first sought to minimize missing data by only including loci that were shared between at least $70 \%$ of the samples (average of $10.45 \%$ missing data) following Eaton et al. (2015). The second dataset comprised all loci shared among a minimum of four individuals in the pyRAD output (average of $39.2 \%$ missing data). For each dataset, five replicates were run from $K=2$ to $K=5$ using default settings with $20 \mathrm{k}$ burn-in steps (during which $\mathrm{F}_{\mathrm{ST}}$ and $\boldsymbol{\alpha}$ sampling stabilized) followed by 20k MCMC steps. Any individuals that were determined to be potentially admixed ( $<95 \%$ any single species) were removed, and we estimated the maximum likelihood phylogeny for the remaining samples following the methods described above.

Assessment of hybridization using Patterson's D.- - In order to assess evidence of hybridization between between three species of lobed-leaf oaks, we employed Patterson's D statistic (Durand et al. 2011; Green et al. 2010) which tests for significant deviation 
from expected proportions of shared biallelic SNPs that are discordant with the species tree ("ABBA-BABA"), which occur in equal frequencies on average between neutrally evolving populations without gene flow. We implemented a four taxon test in PyRAD, using the pectinate topology $(((\mathrm{P} 1, \mathrm{P} 2) \mathrm{P} 3) \mathrm{O})$, where $\mathrm{P} 1=$ Quercus lobata, $\mathrm{P} 2=Q$. gambelii, $\mathrm{P} 3=Q$. macrocarpa, and $\mathrm{O}$ (outgroup) $=Q$. pontica . We chose $Q \cdot$ pontica for the outgroup as it branches earlier relative to the ingroup, and is unlikely to have overlapped in historic range with any of the ingroup taxa. We evaluated all possible quartets containing one of eight $Q$. gambelii, three $Q$. lobata, and nine $Q$. macrocarpa for a total of 216 comparisons. One thousand bootstrap replicates were performed for each comparison, and D-statistics were considered significant if their z-score corresponded to $\mathrm{p}<0.01$ after Holm-Bonferroni correction for multiple comparisons.

Minimizing the signal of $\mathrm{Q}$. gambelii-macrocarpa introgression.- - In initial ranking relatedness analyses, Quercus macrocarpa samples exhibited the highest non-conspecific relatedness value for individuals of $Q$. gambelii, a relationship inconsistent with both the concatenated and species tree analyses. Because of these observations and the proposed historical interaction between these two species (Maze 1968), we sought to remove potential signal of introgression between $Q$. gambelii and $Q$. macrocarpa via a modified reverse successive weighting approach (Trueman 1998) based on decay of likelihood scores when constraints are enforced. Our approach focused on loci for which the monophyly of $Q$. gambelii and $Q$. macrocarpa was a poor fit. For each locus that contained at a minimum one $Q$. gambelii, one $Q$. macrocarpa and two oaks of any other species (filtered this way such that our constraint would not be compatible with all 
possible topological outcomes), we calculated likelihood scores on two neighbor-joining trees: one unconstrained and one in which monophyly of the two species in focus was enforced. All loci for which the likelihood was worse when constrained were concatenated and a maximum likelihood phylogeny was estimated in RAxML under the same parameters used for the total evidence estimate. To further test whether interactions between $Q$. macrocarpa and both $Q$. gambelii and $Q$. lobata were affecting the topology in total evidence analysis, we created and analyzed, in the same manner described above, a subsample comprising loci for which the monophyly of $Q$. gambelii and Q. lobata was a poor fit. If both species or the ancestor to both species interacted historically with $Q$. macrocarpa, our expectation is that analysis of this subsample would recover $Q$. gambelii and $Q$. lobata as aligned with eastern clades, though no longer in a sister relationship with each other.

\section{RESULTS}

Sequencing results. - RAD sequencing of 136 individuals resulted in $2.11 \mathrm{e} 8$ total raw reads of which $1.89 \mathrm{e} 8$ passed quality filtering (per individual mean $=1.40 \mathrm{e} 6$; range 1.08e4-4.68e6, sd =7.73e5). Fastq files are deposited in the Genbank sequence read archive (SRA project PRJNA376740). The pyRAD-clustered dataset consisted of 86,022 total clusters shared among a minimum of four individuals (approximately exponentially distributed; mean $=20.67$, range $=4-126,25$ th -75 th quartiles $=5-23$ ) individuals per cluster; see supplemental information). The three individuals with the poorest 
representation in the final dataset (represented by fewer than 200 clusters) were removed from analyses.

Phylogenetic analysis and Structure results.-The maximum likelihood phylogeny estimated in RAxML (Fig. 2) Within section Quercus (excluding Virentes, Protobalanus and $Q$. sadleriana), we recovered strongly supported clades of California white oaks (Dumosae), two Mexican clades, and three Eastern North American clades (Albae, Prinoideae and Stellatae). Samples of Quercus gambelii and Q. lobata were recovered as each other's closest relatives, composing a clade that was sister to Albae and Prinoideae. The concatenated estimate is largely topologically concordant with the SVD quartetsbased species tree estimate (where the trees can be compared; OTUs are not identical), with the exception of the poorly supported placements of $Q$. gambelii and Q. lobata, with the former falling sister to a clade comprising Albae and Prinoideae, and the latter being sister to all white oaks to the exclusion of Ponticae and Virentes (supplement). Structure analysis detected three potentially admixed individuals among the three species examined: one Q. gambelii from Colorado ( 15\% Q. macrocarpa; our easternmost sample) and two Q. gambelii from Utah ( 10-15\% Q. lobata). To eliminate possible topological effects of these individuals, we removed them from the data matrix and reestimated the phylogeny via RAxML. The resulting topology (not shown) exhibited the same clade-level topology as that of the total evidence tree, suggesting that these putatively admixed individuals were not solely responsible for the observed conflict. 
Ranking relatedness.-For each individual in the dataset, we ranked relatedness of all other individuals based on an aggregation of shortest pairwise distances for each locus; this was completed for the collected dataset and three simulated datasets. Here we focused our assessment of these results on samples of three taxa: Q. gambelii, Q. lobata, and Q. macrocarpa (Fig. 3; see supplemental for complete scores).

Individuals of $Q$. gambelii that were represented by more than 500 loci in the dataset ranked as each other's closest relatives in all but a few cases (Fig 3A). The highest ranking non-conspecific sample to any $Q$. gambelii was an individual of $Q$. macrocarpa; all Q. macrocarpa individuals were typically highly ranked, with a few individuals from the other clades attaining a higher score for some individuals of $Q$. gambelii (e.g., Fig 3A.). Mexican Clade 2 samples composed most of the next tier of ranked individuals for all samples of $Q$. gambelii. Quercus lobata specimens, which are recovered as sister to $Q$. gambelii in the concatenated analysis typically were ranked lower than expected for all individuals. In assessing the significance of rankings for this individual, we focused on the mean rank of Q. macrocarpa specimens (Fig. 3A). Observed rankings were significantly higher $(\mathrm{p}<0.002)$ than the simulated means for all tree depths, with no single simulated mean rank higher (closer to target individual) than the observed value.

For the three samples of $Q$. lobata, conspecifics ranked highest, followed by $Q$. gambelii and Q. macrocarpa (Fig. 3B). This pattern is inconsistent with the rankings observed in the other two species, where Q. lobata was not recovered as a highly ranked taxon. Observed rankings of $Q$. macrocarpa specimens to the Q.lobata individual were 
significantly higher than the simulated means for all tree depths, with no single simulated mean rank higher than the observed value (Fig. 3B).

Individuals of Q. macrocarpa (Bur oak) all ranked as each other's closest relatives, followed by $Q$. gambelii, consistent with the ranking of the latter (Fig. 3C). Ranked next highest were typically a mixture of samples representing Prinoideae and Mexican Clade 2, with $Q$. lobata samples on the lower end. The observed mean rank of Q. gambelii samples was significantly higher than simulated mean ranks at all tree depths (Fig. 3C). For the null comparison, we found that observed mean rank of $Q$. michauxii samples to the Q. macrocarpa samples was significantly lower than simulated mean ranks in two of three depths, with the observed value being greater than three of 500 simulated values ( $p$ $=3 / 500 * 12[$ Holm-Bonferroni correction $]=0.072$ ). Our expectations were that the null observed value would fall within the range of the simulated distributions. The lowerthan-expected value is likely due to interacting taxa (like $Q$. gambelii) "pushing" $Q$. michauxii lower in the rankings.

Detecting hybridization with Patterson's D.--Of 216 four-taxon tests, 102 had significant Z-scores (> $|4.05|$; see summary in Table 1, full results in supplemental material). Six of eight $Q$. gambelii individuals exhibited both significant positive and negative D-statistics. This phenomenon is likely explained by the narrow overlap of the loci shared among individuals across permutations of the four-taxon test. 
Minimizing the Q. macrocarpa-gambelii interaction.-We estimated a maximum likelihood tree for loci whose substitution patterns were incompatible with a sister relationship between $Q$. gambelii and Q. macrocarpa (Fig. 4A). 24,712 of 86,022 passed the initial filtering step for loci that would be potentially informative based on taxon sampling; of these 8,636 had a lower likelihood when monophyly of $Q$. gambelii - $Q$. macrocarpa was enforced. The topology of the subsampled dataset differed from the concatenated topology at two deeper nodes: while Q. lobata and Q. gambelii remained sister (but with poor support), this clade was supported (b.s. =92) as sister to Dumosae. This clade together was recovered as sister to Stellatae and the Mexican clades, whereas it is placed as sister to all section Quercus clades in both the total evidence phylogenetic and species tree estimate. For the second subsampled analysis, in which we filtered loci for those which rejected the monophyly of $Q$. gambelii and Q. lobata $(4,262$ of 15,561), the latter was recovered as sister to the CFP clade, while $Q$. gambelii was recovered as sister to the clade comprising $Q$. bicolor, Q. lyrata and Q. macrocarpa (Fig. 4B).

\section{DISCUSSION}

Our first total evidence (concatenated) maximum likelihood analysis suggested that a clade comprising $Q$. gambelii and Q. lobata was sister to the Eastern North American (ENA) lobed white oaks, and more distantly related to the white oaks of the California Floristic Province (CFP). Though strongly supported, this result was only recovered when both $Q$. gambelii and $Q$. macrocarpa were analyzed in combination, suggesting that the result was an artifact of taxon sampling. Based on the additional locus- 
partitioning analyses presented in this paper, we consider this total-evidence topology to be misleading: the primary signal of lineage divergence is overwhelmed in this topology by a history of introgression among $Q$. gambelii, Q. lobata, and $Q$. macrocarpa. This conclusion is supported by four lines of evidence: sensitivity of the topology to taxon sampling (as mentioned above); rank of relatedness among individuals and four-taxon test, which demonstrate a significantly high degree of allele sharing between $Q$. gambelii and $Q$. macrocarpa; and the strongly supported secondary signal of monophyly of the CFP oaks, when loci supporting the primary topology are removed. We interpret these results with caution, but conclude that the placement of the Q. gambelii-Q. lobata lineage in the concatenated estimate as sister to eastern oak clades is likely the result of shared, introgressed alleles between $Q$. gambelii, and possibly Q. lobata, and Q. macrocarpa, "pulling" the western species away from the CFP oaks and towards the ENA clades.

Our inference that our phylogenetic results are due to historical rather than contemporary gene flow is supported by the fact that Q. gambelii, Q. macrocarpa, and Q. lobata are strongly monophyletic across analyses. All individuals of these species form tight, cohesive clades, and all individuals of each species shows the same pattern in rank of relatedness among species with little exception. The one pairwise comparison in which we observed an interruption of a species (Fig 3A) in rank order may be the result of more recent introgression with Mexican oaks along the lineage history of the aberrant sample (Q. gambelii sample PM237 from New Mexico, where it is sympatric with Mexican oak species; see supplement). In cases of regional or more local gene flow, introgressed individuals generally fall sister to a core of the species, and their removal is expected to 
render the species monophyletic (Eaton et al. 2015; Eaton and Ree 2013; McDade 1990; McDade 1992). Our data show no such pattern. Moreover, Structure analysis shows very little admixture in our study: we would expect to find evidence of admixture at the individual level if our results were the outcome of contemporary gene flow. What admixture is seen may be difficult to interpret, owing to unknown interactions with Mexican clade 2 individuals that are not sampled in this study. The four-taxon test performed using Patterson's D statistic resulted in strong evidence for gene flow between Q. macrocarpa and both $Q$. lobata and $Q$. gambelii, however results of permutations that contained the same individual $Q$. gambelii exhibited strongly supported conflicting patterns of gene flow (i.e., ABBA vs BABA); overall six of eight individuals showed this pattern. These discordant patterns may arise from the lack of connectivity, or "sharedness", of loci across four-taxon permutations. Additionally, our particular case made it difficult to set up the test, given that 1) the underlying species tree is not clear, and 2) the outgroup was difficult to choose, due both to the first problem, as well as potential interactions of outgroup candidates that overlap in range, or are though to have historically shared habitat. Our outgroup choice, $Q$. pontica, is distantly related to the ingroup taxa, an attribute which may lead to false positive detection of gene flow in some cases (Eaton and Ree 2013). Our rank of relatedness approach offers a more global perspective of conflicting signal across the dataset; however, tests of significance should be targeted to a single individual to avoid overestimating significance of outcomes while performing multiple comparisons. 
It is worth noting that despite $Q$. gambelii's reputation for hybridization with a diverse assemblage of white oak species distributed in the southwestern U.S. (Tucker 1961), we found little evidence of gene flow between $Q$. gambelii and those species sampled in this study. The $Q$. undulata complex is thought to entail a syngameon among $Q$. arizonica, $Q$. grisea, Q. havardii, Q. mohriana, Q. muehlenbergii, and Q. turbinella, with $Q$. gambelii at the center of these interactions (Tucker 1961). We included at least one individual of each of these species in our analysis, and none appear to share more alleles with $Q$. gambelii than expected by their phylogenetic position, based on the rank of relatedness analyses (supplement). Moreover, Q. gambelii exhibited no phylogenetic movement toward species in the Mexican oak clades when secondary topologies (using reverse successive weighting) were estimated (Fig 4). Interestingly, the Mexican samples were clustered near the top of the relatedness rankings among the three species in focus, which was not expected under any simulations of ILS (supplement). These rankings are not surprising given the degree to which these species overlap; in particular Q. gambelii is currently sympatric or at least geographically proximal to members of this clade. These results most likely reflect contemporary or recent gene flow, but additional sampling is needed to investigate this pattern. Surprisingly, the lobed-leaf $Q$. garryana aligned more consistently with California white oak species (including members of Dumosae and Mexican Clade 2) than with the other lobed western oaks. This may be due to limited interactions between $Q$. garryana and $Q$. lobata, whose ranges overlap narrowly.

While most studies of oak hybridization have documented current gene flow among sympatric species, there have been a few claims of historical secondary contact between species that are now distributed allopatrically (Eaton et al. 2015; Maze 1968). 
Macrofossil evidence is clear on how climate change has shaped oak distributions through the last 15 million years (for review see Betancourt et al. 1990; Graham 1999). Leaf fossils from Late Miocene to the Pliocene show that lobed-leaf white oaks (e.g., $Q$. prelobata) had a distribution further north, with a notable density in the region of east central Oregon (e.g., John Day fossil beds), and into southeastern Washington and southwestern Idaho, essentially in areas that no longer harbor oaks (for review see Mensing 2015). Our results are consistent with a broad contact zone between ancestral populations $Q$. gambelii and $Q$. macrocarpa (Fig. 5). However, it's also possible that $Q$. gambelli is a stabilized species of hybrid origin between disjunct populations of a taxon like Q. prelobata and Q. macrocarpa that has become homogenized through time. While distinguishing between these two scenarios may be difficult with RADseq data, it would not be surprising to discover an oak species derived through hybridization. Interestingly, hypotheses of past hybridization between $Q$. gambelii and Q. macrocarpa during the Pleistocene, when oak distribution expanded again, have been used to explain intermediate phenotypes in western North Dakota and northeastern New Mexico, areas where only one the species occur today (Maze 1968). Based on the lack of evidence suggesting direct interactions between $Q$. macrocarpa and $Q$. lobata, we reject that observed topology is the result of historical exchange between ancestral populations of $Q$. macrocarpa and the ancestor of $Q$. gambelii and $Q$. lobata, though we recognize that this scenario is not incompatible if subsequent exchange between $Q$. lobata and other white oaks in the CFP obscured the primary phylogenetic signal. We observed some evidence for recent admixture between $Q$. gambelii and both $Q$. macrocarpa and Q. lobata, in samples collected from the eastern and western edges of the $Q$. gambelii range. In sum, 
there may have been at least two temporally distinct rounds of introgression affecting the phylogenetic position of the Q. gambelii and Q. lobata lineage.

Behavior of hybrids in a phylogenetic analysis. The discovery of hybrids in a phylogenetic context has often been a happy accident of observed incongruence among the markers selected (e.g., Rieseberg and Soltis 1991). With the high volumes of data we now obtain in phylogenomic datasets, the need to carefully subset loci and investigate secondary signals demands attention to weakly supported or unexpected resolutions in the phylogeny. At the risk of fishing for interesting results, phylogeneticists need to pay attention to possible areas of discordance in their phylogenies and begin to investigate whether first impressions that something is amiss are actually born of genealogical discordance. In any case where historical hybridization is suspected, application of a bifurcating model of evolution is not an ideal approach. Network-based phylogenetic analyses seek to accommodate these processes (Nakhleh et al. 2005; Yu et al. 2014; Yu and Nakhleh 2015; Yu et al. 2013), however the potential myriad of genetic exchanges among sympatric oak species across time and space makes the task of modeling these reticulation events daunting and currently intractable. Yet, the concatenated approach and the targeted downstream analyses of relationships presented here complement other SNPbased methods (Durand et al. 2011; Eaton et al. 2015; Eaton and Ree 2013; Green et al. 2010; Pease and Hahn 2015) and provide a framework for tackling this task, leading to more pointed and potentially more powerful hypothesis testing, particularly as we collect more robust genomic resources (transcriptomes, whole genomes) for these taxa (Payseur and Rieseberg 2016). 


\section{ACKNOWLEDGMENTS}

This study was funded by National Science Foundation awards to ALH (Awards 1146488) and PSM (Award 1146102). We especially acknowledge Marlene Hahn (The Morton Arboretum, Lisle, IL, USA) for sample preparation and curation of metadata and specimens for the RADseq dataset. For help collecting oaks, we also thank Dylan Burge, Ed Cope, Paul Gugger, Allen Hauser, Tristan Hauser, David Hillis, Leigh Johnson, Tyler Lacy, Michael Mesler, Chris Reid Andrew Ruple, Bob Shriver, and Erin Tripp. For helpful discussion, we thank Dave Swofford.

\section{LITERATURE CITED}

Antonecchia, G., Fortini, P., Lepais, O., Gerber, S., Legér, P., Scippa, G.S., and Viscosi, V. 2015. Genetic structure of a natural oak community in central Italy: Evidence of gene flow between three sympatric white oak species (Quercus, Fagaceae). Annals of Forest Research 58(2): 205-216.

Arnold, M.L. 2015. Divergence with genetic exchange. Oxford University Press.

Baird, N.A., Etter, P.D., Atwood, T.S., Currey, M.C., Shiver, A.L., Lewis, Z.A., Selker, E.U., Cresko, W.A., and Johnson, E.A. 2008. Rapid SNP Discovery and Genetic Mapping Using Sequenced RAD Markers. PLoS ONE 3(10): e3376.

Bapteste, E., van Iersel, L., Janke, A., Kelchner, S., Kelk, S., McInerney, J.O., Morrison, D.A., Nakhleh, L., Steel, M., and Stougie, L. 2013. Networks: expanding evolutionary thinking. Trends in Genetics 29(8): 439-441. 
Belahbib, N., Pemonge, M.H., Ouassou, A., Sbay, H., Kremer, A., and Petit, R. 2001. Frequent cytoplasmic exchanges between oak species that are not closely related:

Quercus suber and Q. ilex in Morocco. Molecular Ecology 10(8): 2003-2012.

Betancourt, J.L., Van Devender, T.R., and Martin, P.S. 1990. Packrat middens: the last 40,000 years of biotic change. University of Arizona Press.

Camus, A. 1936-1954. Les chênes: monographie du genre Quercus. P. Lechevalier, Paris. Cavender-Bares, J., Gonzalez-Rodriguez, A., Eaton, D.A.R., Hipp, A.L., Beulke, A., and Manos, P.S. 2015. Phylogeny and biogeography of the American live oaks (Quercus subsection Virentes): A genomic and population genetics approach. Molecular Ecology 24(14): 3668-3687.

Chifman, J., and Kubatko, L. 2014. Quartet inference from SNP data under the coalescent model. Bioinformatics 30(23): 3317-3324.

Chifman, J., and Kubatko, L. 2015. Identifiability of the unrooted species tree topology under the coalescent model with time-reversible substitution processes, site-specific rate variation, and invariable sites. Journal of Theoretical Biology 374: 35-47.

Craft, K.J., Ashley, M.V., and Koenig, W.D. 2002. Limited hybridization between Quercus lobata and Quercus douglasii (Fagaceae) in a mixed stand in central coastal California. American Journal of Botany 89(11): 1792-1798.

Dodd, R.S., and Afzal-Rafii, Z. 2004. Selection and disperal in a multispecies oak hybrid zone. Evolution 58(2): 261-269.

Durand, E.Y., Patterson, N., Reich, D., and Slatkin, M. 2011. Testing for ancient admixture between closely related populations. Molecular Biology and Evolution 28(8): 2239-2252. 
Eaton, D.A.R. 2014. PyRAD: assembly of de novo RADseq loci for phylogenetic analyses. Bioinformatics. 30(13): 1844-1849.

Eaton, D.A.R., Hipp, A.L., González-Rodríguez, A., and Cavender-Bares, J. 2015. Historical introgression among the American live oaks and the comparative nature of tests for introgression. Evolution 69(10): 2587-2601.

Eaton, D.A.R., and Ree, R.H. 2013. Inferring phylogeny and introgression using RADseq data: an example from flowering plants (Pedicularis: Orobanchaceae). Systematic Biology 62(5): 689-706.

Gailing, O., and Curtu, A.L. 2014. Interspecific gene flow and maintenance of species integrity in oaks. Annals of Forest Research 57(1): 5.

Graham, A. 1999. Late Cretaceous and Cenozoic history of North American vegetation: north of Mexico. Oxford University Press on Demand.

Grant, V.E. 1981. Plant Speciation. Second ed. Columbia University Press.

Green, R.E., Krause, J., Briggs, A.W., Maricic, T., Stenzel, U., Kircher, M., Patterson, N., Li, H., Zhai, W., Fritz, M.H.-Y., Hansen, N.F., Durand, E.Y., Malaspinas, A.-S., Jensen, J.D., Marques-Bonet, T., Alkan, C., Prüfer, K., Meyer, M., Burbano, H.A., Good, J.M., Schultz, R., Aximu-Petri, A., Butthof, A., Höber, B., Höffner, B., Siegemund, M., Weihmann, A., Nusbaum, C., Lander, E.S., Russ, C., Novod, N., Affourtit, J., Egholm, M., Verna, C., Rudan, P., Brajkovic, D., Kucan, Ž., Gušic, I., Doronichev, V.B., Golovanova, L.V., Lalueza-Fox, C., de la Rasilla, M., Fortea, J., Rosas, A., Schmitz, R.W., Johnson, P.L.F., Eichler, E.E., Falush, D., Birney, E., Mullikin, J.C., Slatkin, M., Nielsen, R., Kelso, J., Lachmann, M., Reich, D., and Pääbo, S. 2010. A Draft sequence of the Neandertal genome. Science 328(5979): 710-722. 
Hardin, J.W. 1975. Hybridization and introgression in Quercus alba. Journal of the Arnold Arboretum 56(3): 336-363.

Hasegawa, M., Kishino, H., and Yano, T. 1985. Dating of the human-ape splitting by a molecular clock of mitochondrial DNA. Journal of Molecular Evolution 22(2): 160-174. Hipp, A.L. 2015. Should Hybridization Make Us Skeptical of the Oak Phylogeny? International Oak Journal 26: 9-18.

Hipp, A.L., Eaton, D.A.R., Cavender-Bares, J., Fitzek, E., Nipper, R., and Manos, P.S. 2014. A framework phylogeny of the American oak clade based on sequenced RAD data. PLoS ONE 9: e93975.

Hipp, A.L., and Weber, J.A. 2008. Taxonomy of Hill's Oak (Quercus ellipsoidalis: Fagaceae): Evidence from AFLP Data. Systematic Botany 33(1): 148-158.

Howard, D., Preszler, R., Williams, J., Fenchel, S., and Boecklen, W. 1997. How discrete are oak species? Insights from a hybrid zone between Quercus grisea and Quercus gambelii. Evolution 51(3): 747 - 755.

Kremer, A., Dupouey, J., Deans, J., Cottrell, J., Csaikl, U., Finkeldey, R., Espinel, S., Jensen, J., Kleinschmit, J., Van Dam, B., Ducousso, A., Forrest, I., Lopez de Heredia, U., Lowe, A., Tutkova, M., Munro, R., Steinhoff, S., and Badeau, V. 2002. Leaf morphological differentiation between Quercus robur and Quercus petraea is stable across western European mixed oak stands. Annals of Forest Science 59(7): 777-787. Lefort, F., and Douglas, G.C. 1999. An efficient micro-method of DNA isolation from mature leaves of four hardwood tree species Acer, Fraxinus, Prunus and Quercus. Annals of Forest Science 56(3): 259-263. 
Lepais, O., and Bacles, C.F. 2014. Two are better than one: combining landscape genomics and common gardens for detecting local adaptation in forest trees. Molecular Ecology 23(19): 4671-4673.

Leroy, T., Roux, C., Villate, L., Bodénès, C., Romiguier, J., Paiva, J.A., Dossat, C., Aury, J.M., Plomion, C., and Kremer, A. 2017. Extensive recent secondary contacts between four European white oak species. New Phytologist. doi: 10.1111/nph.14413.

Lind, J.F., and Gailing, O. 2013. Genetic structure of Quercus rubra L. and Quercus ellipsoidalis EJ Hill populations at gene-based EST-SSR and nuclear SSR markers. Tree Genetics \& Genomes 9(3): 707-722.

Maddison, W.P., and Maddison, D.R. 2011. Mesquite: a modular system for evolutionary analysis.

Manos, P.S. 2016. Systematics and biogeography of the American oaks. International Oak Journal 27: 23-36.

Maze, J. 1968. Past hybridization between Quercus macrocarpa and Quercus gambelii. Brittonia 20(4): 321-333.

McDade, L. 1990. Hybrids and phylogenetic systematics I. Patterns of character expression in hybrids and their implications for cladistic analysis. Evolution: 1685-1700. McDade, L.A. 1992. Hybrids and Phylogenetic Systematics II. The Impact of Hybrids on Cladistic Analysis. Evolution 46(5): 1329-1346.

Mirarab, S., Reaz, R., Bayzid, M.S., Zimmermann, T., Swenson, M.S., and Warnow, T. 2014. ASTRAL: genome-scale coalescent-based species tree estimation. Bioinformatics 30(17): i541-i548. 
Muir, G., Fleming, C.C., and Schlötterer, C. 2000. Species status of hybridizing oaks. Nature 405(6790): 1016.

Muller, C.H. 1951. The oaks of Texas. Texas Research Foundation.

Nakhleh, L. 2013. Computational approaches to species phylogeny inference and gene tree reconciliation. Trends in Ecology \& Evolution 28(12): 719-728.

Nakhleh, L., Warnow, T., Linder, C., and St. John, K. 2005. Reconstructing reticulate evolution in species-theory and practice. Journal of Computational Biology 12(6): 796 811.

Nixon, K.C., and Muller, C.H. 1997. Quercus Linnaeus sect. Quercus. In Flora of North America, Vol. 3. Edited by F.o.N.A.E. Committee. Oxford University Press, New York. pp. 471-506.

O'Neill, E.M., Schwartz, R., Bullock, C.T., Williams, J.S., Shaffer, H.B., Aguilar Miguel, X., Parra - Olea, G., and Weisrock, D.W. 2013. Parallel tagged amplicon sequencing reveals major lineages and phylogenetic structure in the North American tiger salamander (Ambystoma tigrinum) species complex. Molecular Ecology 22(1): 111-129. Paradis, E. 2011. Analysis of Phylogenetics and Evolution with R. Springer Science \& Business Media.

Paradis, E., Claude, J., and Strimmer, K. 2004. APE: Analyses of phylogenetics and evolution in R language. Bioinformatics 20(2): 289-290.

Payseur, B.A., and Rieseberg, L.H. 2016. A genomic perspective on hybridization and speciation. Molecular Ecology 25: 2337-2360. 
Pearse, I.S., and Hipp, A.L. 2009. Phylogenetic and trait similarity to a native species predict herbivory on non-native oaks. Proceedings of the National Academy of Sciences of the United States of America 106(43): 18097-18102.

Pease, J.B., and Hahn, M.W. 2015. Detection and polarization of introgression in a fivetaxon phylogeny. Systematic Biology 64(4): 651-662.

Phillips, M.J., Delsuc, F., and Penny, D. 2004. Genome-scale phylogeny and the detection of systematic biases. Molecular Biology and Evolution 21(7): 1455-1458. Piednoël, M., Aberer, A.J., Schneeweiss, G.M., Macas, J., Novak, P., Gundlach, H., Temsch, E.M., and Renner, S.S. 2012. Next-generation sequencing reveals the impact of repetitive DNA across phylogenetically closely related genomes of Orobanchaceae. Molecular Biology and Evolution 29(11): 3601-3611.

Pritchard, J., Stephens, M., and Donnelly, P. 2000. Inference of population structure using multilocus genotype data. Genetics 155(2): 945 - 959.

Prum, R.O., Berv, J.S., Dornburg, A., Field, D.J., Townsend, J.P., Lemmon, E.M., and Lemmon, A.R. 2015. A comprehensive phylogeny of birds (Aves) using targeted nextgeneration DNA sequencing. Nature 526: 569-573.

R Core Team. 2016. R: A language and environment for statistical computing. R Foundation for Statistical Computing, Vienna, Austria. 2015. Available from http://www.R-project.org.

Rambaut, A., and Grassly, N.C. 1997. Seq-Gen: An application for the Monte Carlo simulation of DNA sequence evolution along phylogenetic trees. Computer Applications in the Biosciences 13(3): 235-238. 
Rieseberg, L.H., and Soltis, D. 1991. Phylogenetic consequences of cytoplasmic gene flow in plants. Evolutionary Trends in Plants 5(1): 65-84.

Stamatakis, A. 2006. Phylogenetic models of rate heterogeneity: a high performance computing perspective. In Proceedings 20th IEEE International Parallel \& Distributed Processing Symposium. IEEE. p. 8 pp.

Stamatakis, A. 2014. RAxML version 8: a tool for phylogenetic analysis and postanalysis of large phylogenies. Bioinformatics 30(9): 1312-1313.

Swofford, D.L. 2003. PAUP*. Phylogenetic Analysis Using Parsimony (*and Other Methods). Sinauer Associates, Sunderland, Massachusetts.

Swofford, D.L. 2016. PAUP* test version 4a150.

Trelease, W. 1924. The American oaks. Memoirs of the National Academy of Sciences 20: $1-255$.

Trueman, J.W. 1998. Reverse successive weighting. Systematic Biology 47(4): 733-737. Tucker, J.M. 1961. Studies in the Quercus undulata complex. I. A preliminary statement. American Journal of Botany 48(3): 202-208.

Tucker, J.M. 1963. Studies in the Quercus undulata complex. III. The contribution of $Q$. arizonica. American Journal of Botany 50(7): 699-708.

Yu, Y., Dong, J., Liu, K.J., and Nakhleh, L. 2014. Maximum likelihood inference of reticulate evolutionary histories. Proceedings of the National Academy of Sciences 111(46): 16448-16453.

Yu, Y., and Nakhleh, L. 2015. A maximum pseudo-likelihood approach for phylogenetic networks. BMC Genomics 16(Suppl. 10): S10. 
Yu, Y., Ristic, N., and Nakhleh, L. 2013. Fast algorithms and heuristics for phylogenomics under ILS and hybridization. BMC Bioinformatics 14(15): 1-10.

Zeng, Y.-F., Liao, W.-J., Petit, R.J., and Zhang, D.-Y. 2010. Exploring species limits in two closely related chinese oaks. PLoS ONE 5(11): e15529. 
Table 1. Results of four-taxon test of Patterson's D-statistics of species tree topology $(((\mathrm{P} 1, \mathrm{P} 2) \mathrm{P} 3) \mathrm{O})$, where $\mathrm{P} 1=$ Quercus lobata, $\mathrm{P} 2=$ Q. gambelii, $\mathrm{P} 3=$ Q. macrocarpa, and $\mathrm{O}=Q$. pontica. Shown are $Q$. gambelii specimens. Value of third and fourth columns show number of tests (out of 27 total for each individual) that showed significantly positive (ABBA) and negative (BABA) D-scores, respectively.

\section{Table 1.}

Introgressed with $Q$. macrocarpa:

\begin{tabular}{llrr}
\hline Sample & State & Q. gambelii & Q. lobata \\
\hline MOR_387 & Colorado & 13 & 2 \\
MOR_546 & Arizona & 0 & 15 \\
PM_235 & New Mexico & 0 & 7 \\
PM_236 & New Mexico & 9 & 6 \\
PM_237 & New Mexico & 4 & 6 \\
PM_238 & New Mexico & 10 & 5 \\
PM_241 & Utah & 5 & 7 \\
PM_242 & Utah & 8 & 4 \\
\hline
\end{tabular}


Figure 1. Range map and leaf silhouettes of targeted white oaks species in southwestern North America and the California Floristic Province. Species range shape files downloaded from Little's Atlas of United States Trees (http://gec.cr.usgs.gov/data/little/).

Figure 2. Maximum likelihood phylogenetic estimate of the complete concatenated RADseq dataset. Colored nodes correspond with species and clade identities presented on map and in other figures.

Figure 3. Observed and simulated ranks of relatedness for A) Quercus gambelii specimen MOR 387 from Colorado, USA; B) Q. lobata specimen MOR_123 from California, USA, and C) and D) Q. macrocarpa specimen MOR 356 from Illinois, USA. The left panel of each test represents the ranks, from top to bottom of the observed data, with bar colors representing species. The right panel shows box mean ranks of targeted species, indicated above observed statistic ( $=$ red) line, of 500 datasets simulated at three coalescent depths (N-generations).

Figure 4. Modified depiction of maximum likelihood phylogenetic estimates of subsamples that reject monophyly of A) Q. macrocarpa and Q. gambelii and B) $Q$. gambelii and Q. lobata; C) collapsed topology of unconstrained estimate. Circles at nodes represent bootstrap support greater than $70 \%$. Subclades sizes and branch lengths have been modified for simplicity and are not to scale. 
Figure 5. Plausible scenarios for historical genetic exchange among three oak species across time. 1) Recent interactions between $Q$. lobata and $Q$. gambelii via range expansions during glacial cycles; 2) Recent and historical interactions between $Q$. gambelii or 3) ancestor to $Q$. gambelii and Q. lobata (possibly Q. prelobata), and $Q$. macrocarpa when during periods of range overlap, and 4) a less likely scenario of a stabilized hybrid formed between historical ancestral populations of Q. lobata ancestor and Q. macrocarpa. Fading of deepest branches indicates that these are not sister clades. 


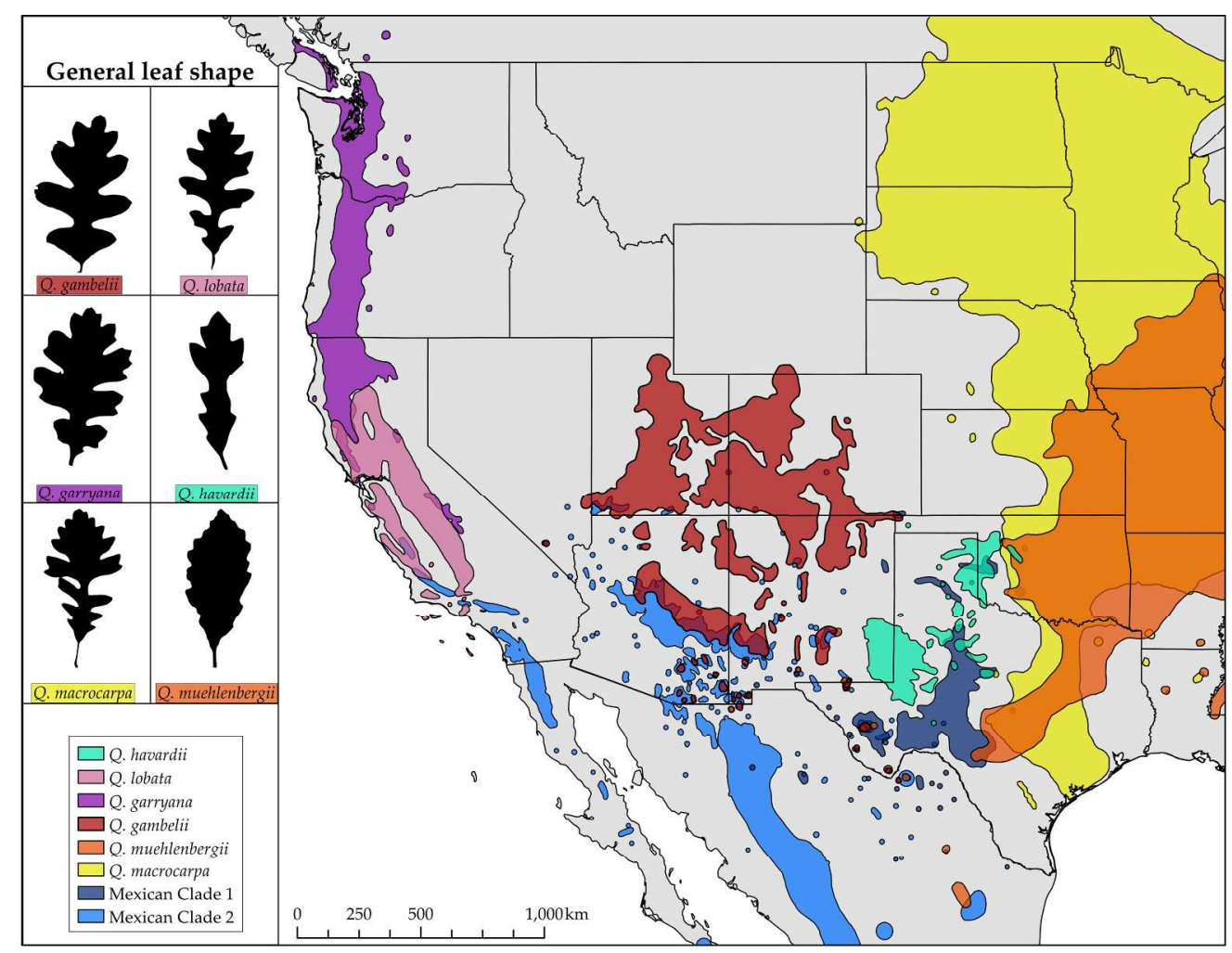

$222 \times 176 \mathrm{~mm}(300 \times 300 \mathrm{DPI})$ 


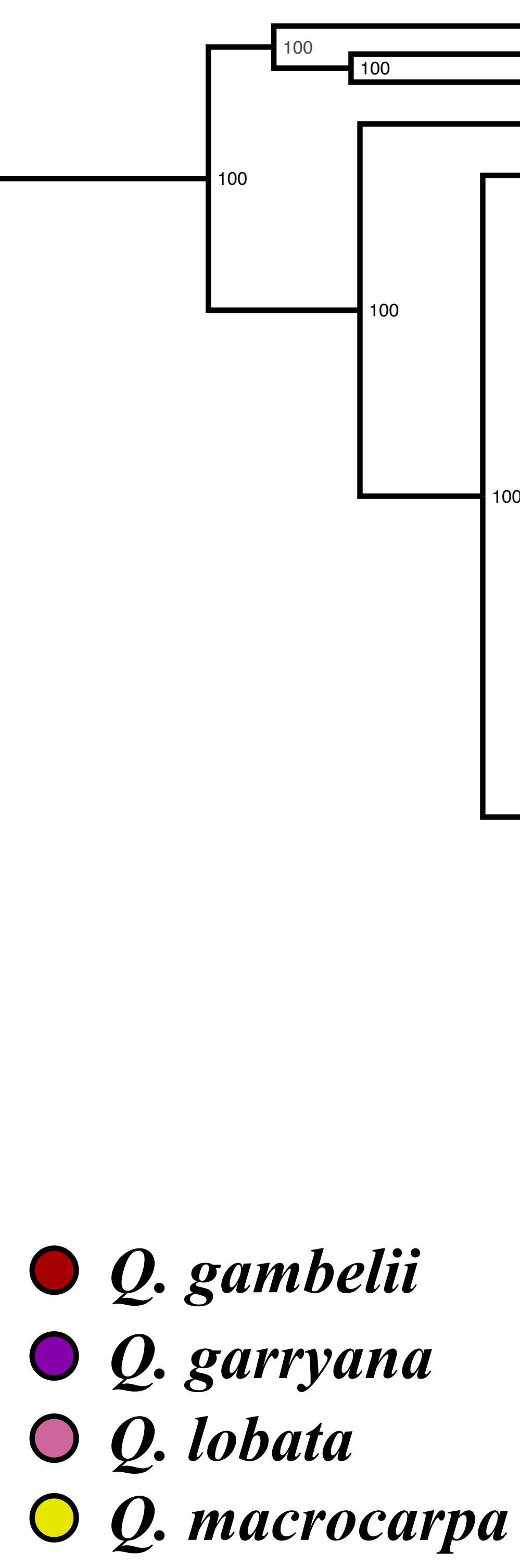

100 PM_244_Q.cedrosensis
MOR_135_Q.cedrosensis

100 POR_377_Q.vacciniifolia

$100+$ T100 PM_103a_Q.psadleriana
PM_321_Q.sadleriana

100
PM_324_Q.garryana_small
MOR_422_Q.garryana_v.breweri

40

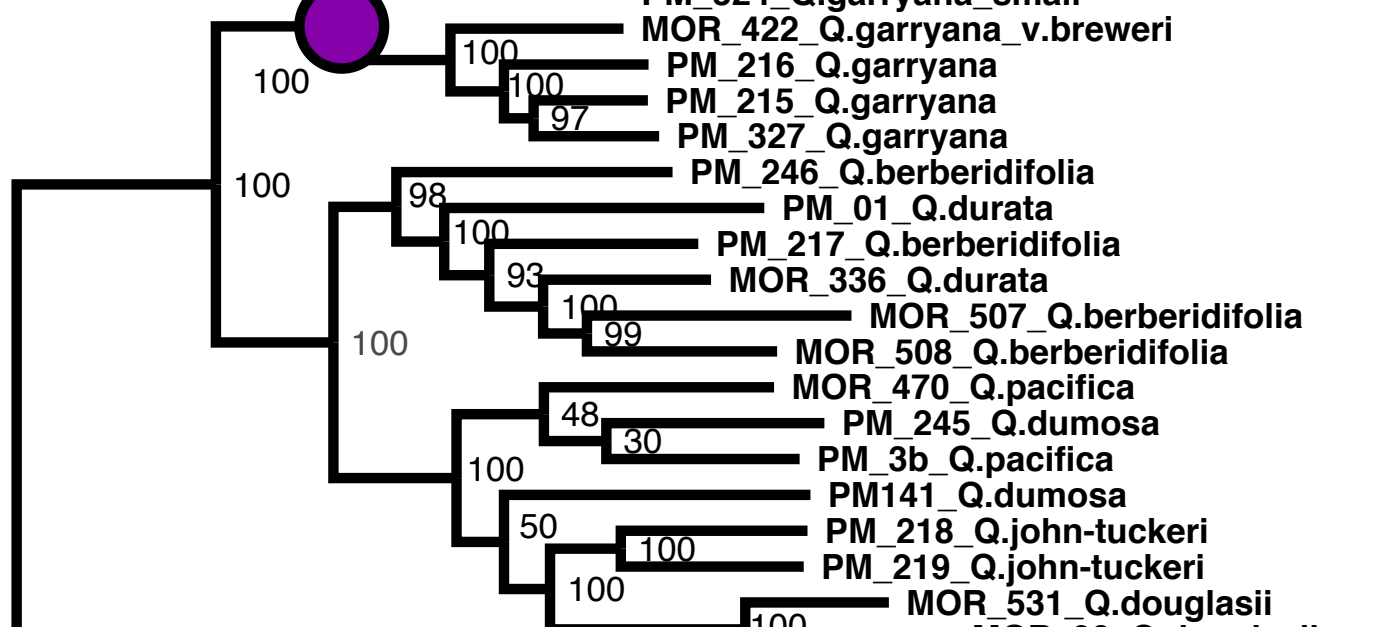

Dumosae

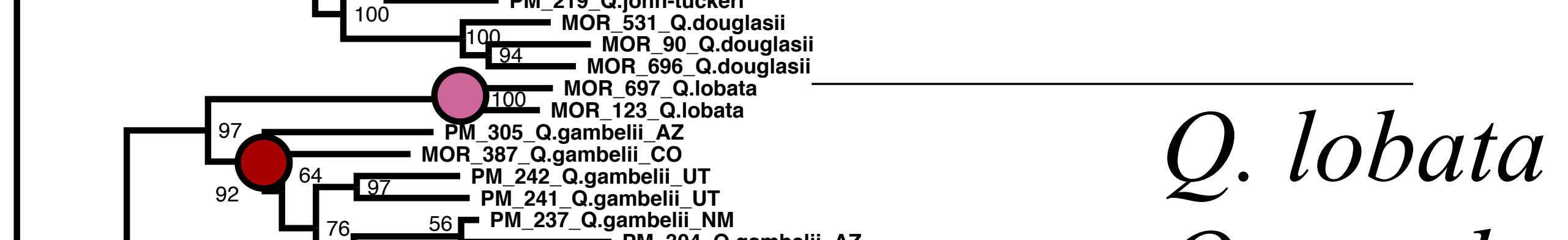

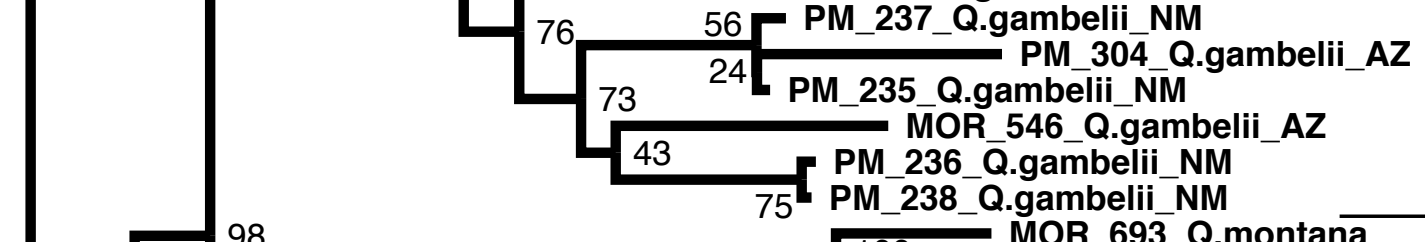

Q. gambelii

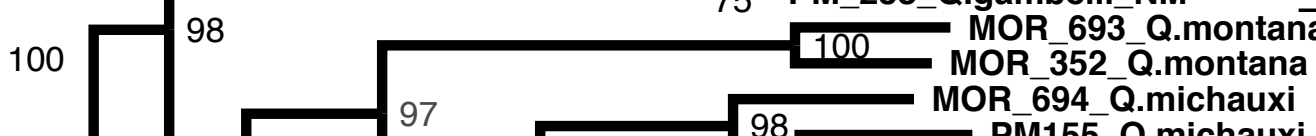

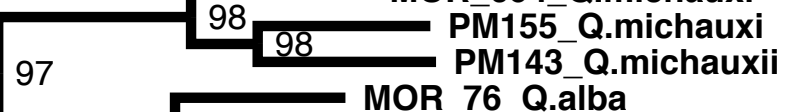

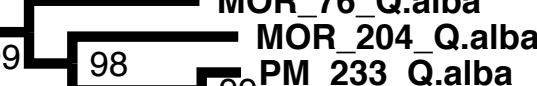

Albae

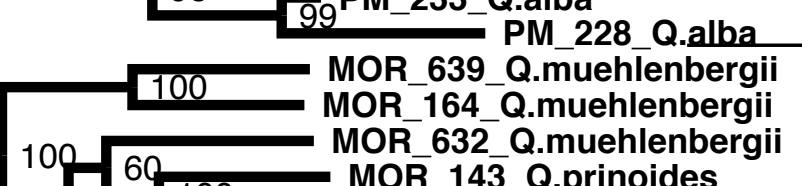

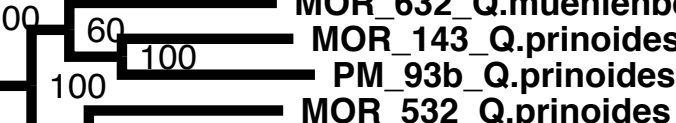

102-MOB

(

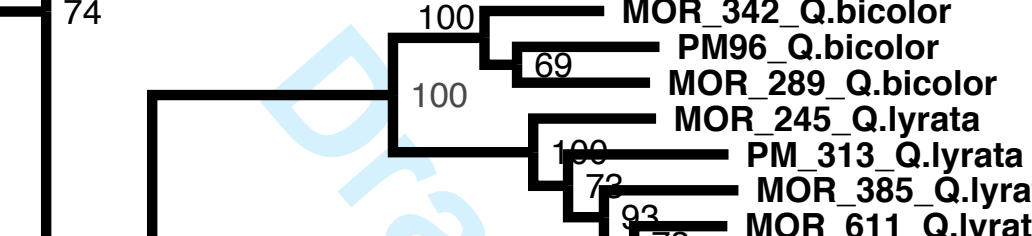

Prinoideae

Q. gambelii

Q. garryana

Q. lobata

macrocarpa

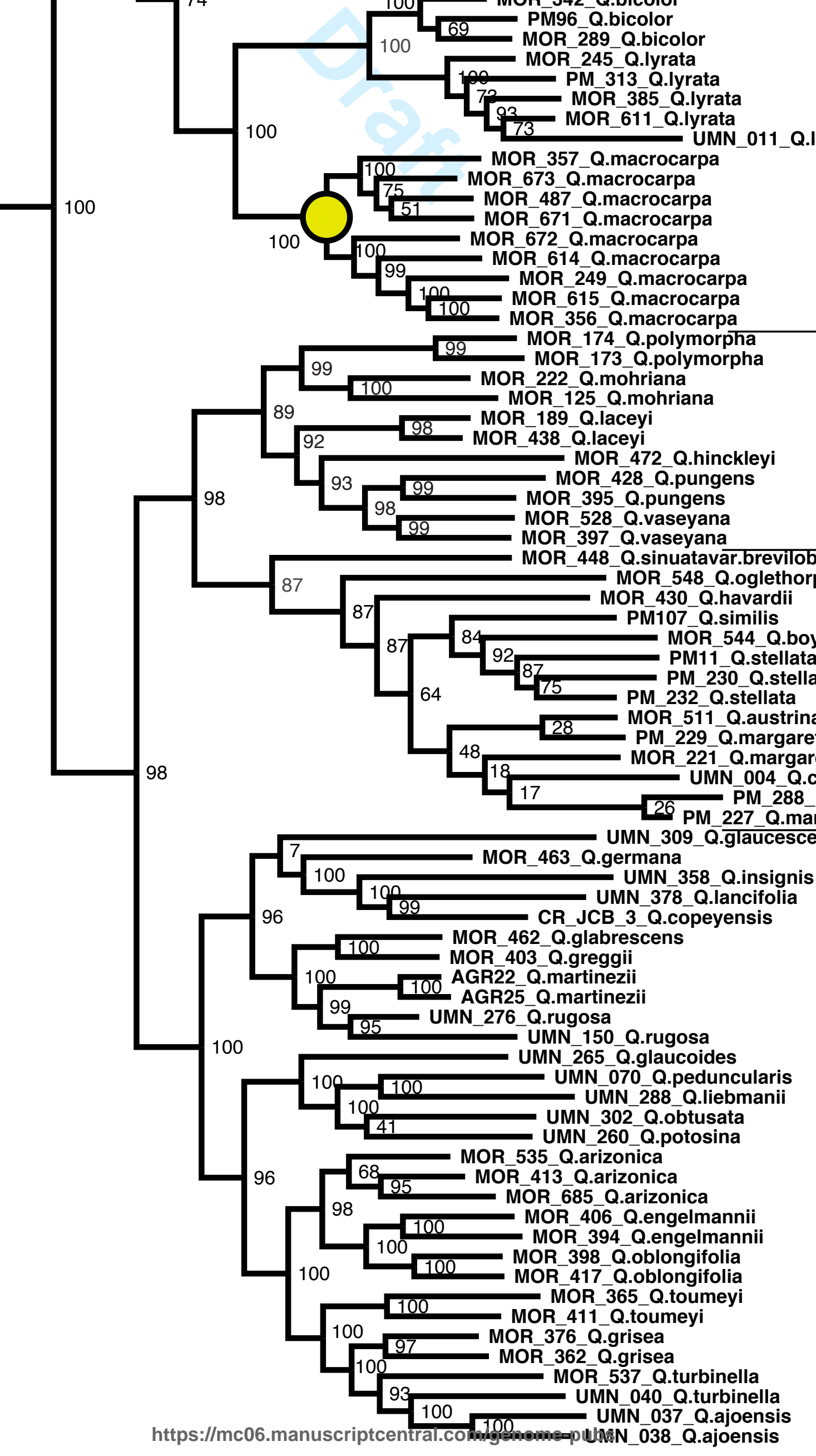

Mexican 2

\section{Stellatae}


A. Q. gambelii

OBSERVED

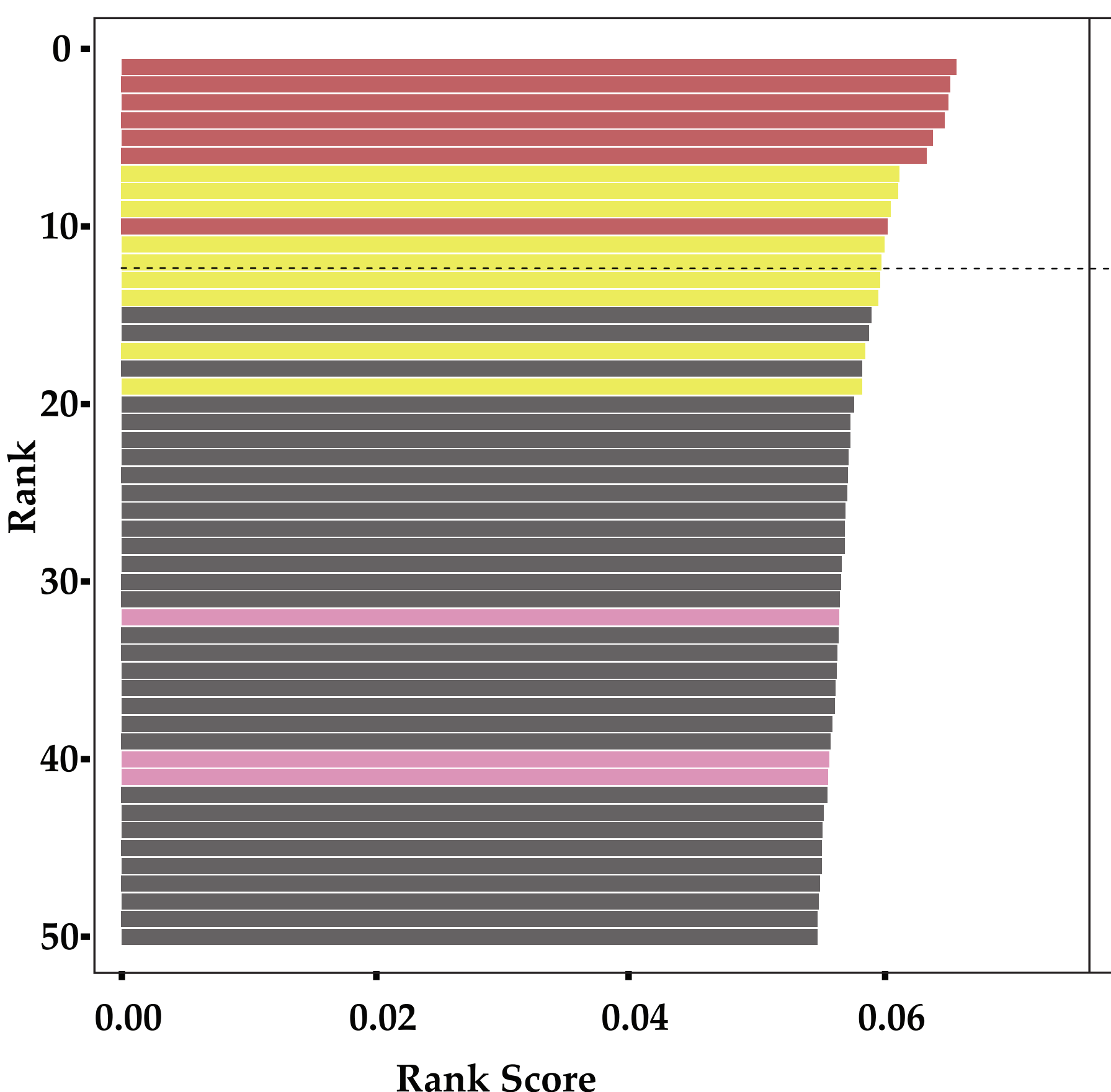

C. Q. macrocarpa - Q. gambelii

OBSERVED

SIMULATIONS

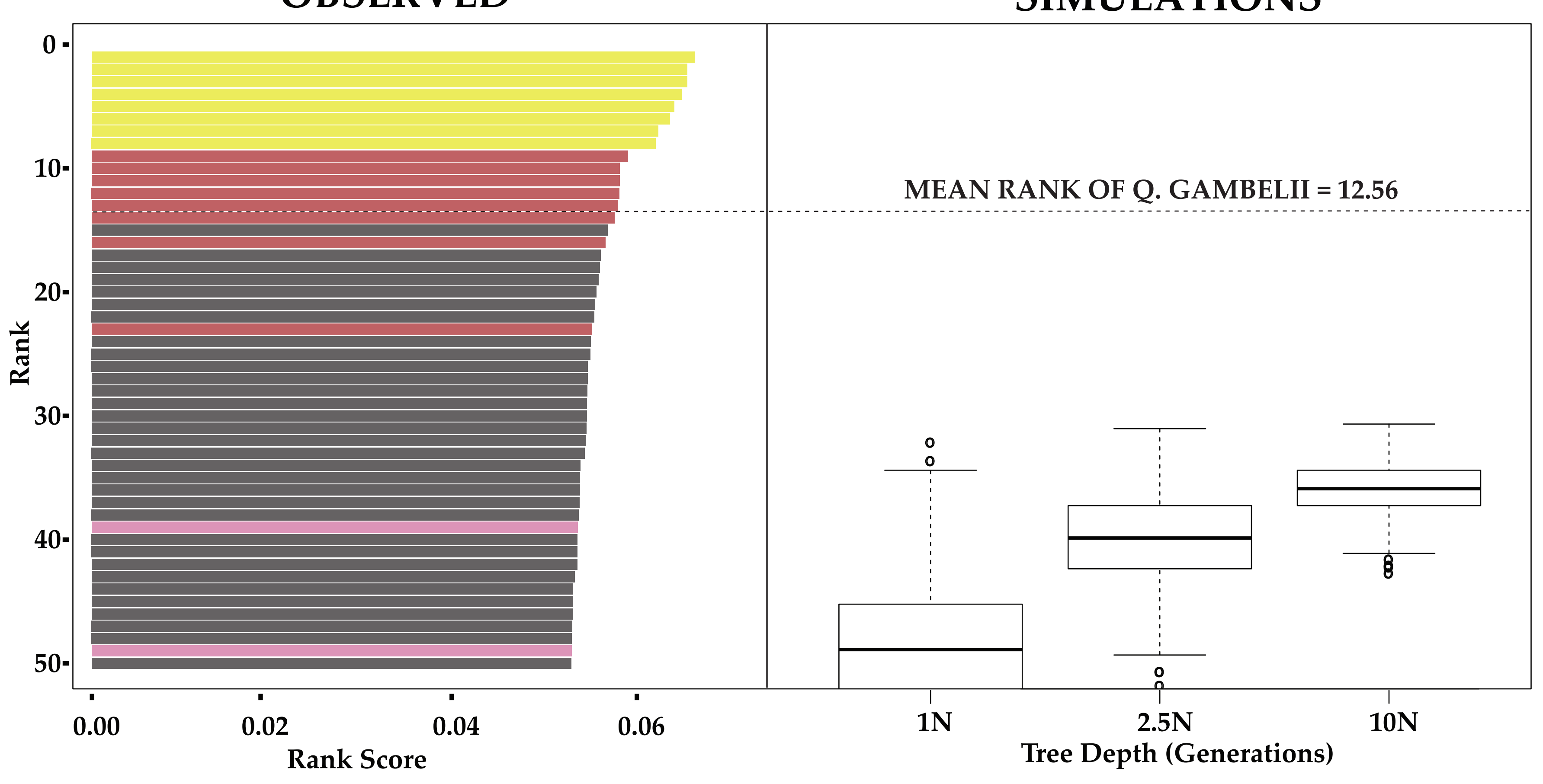

B. Q. lobata

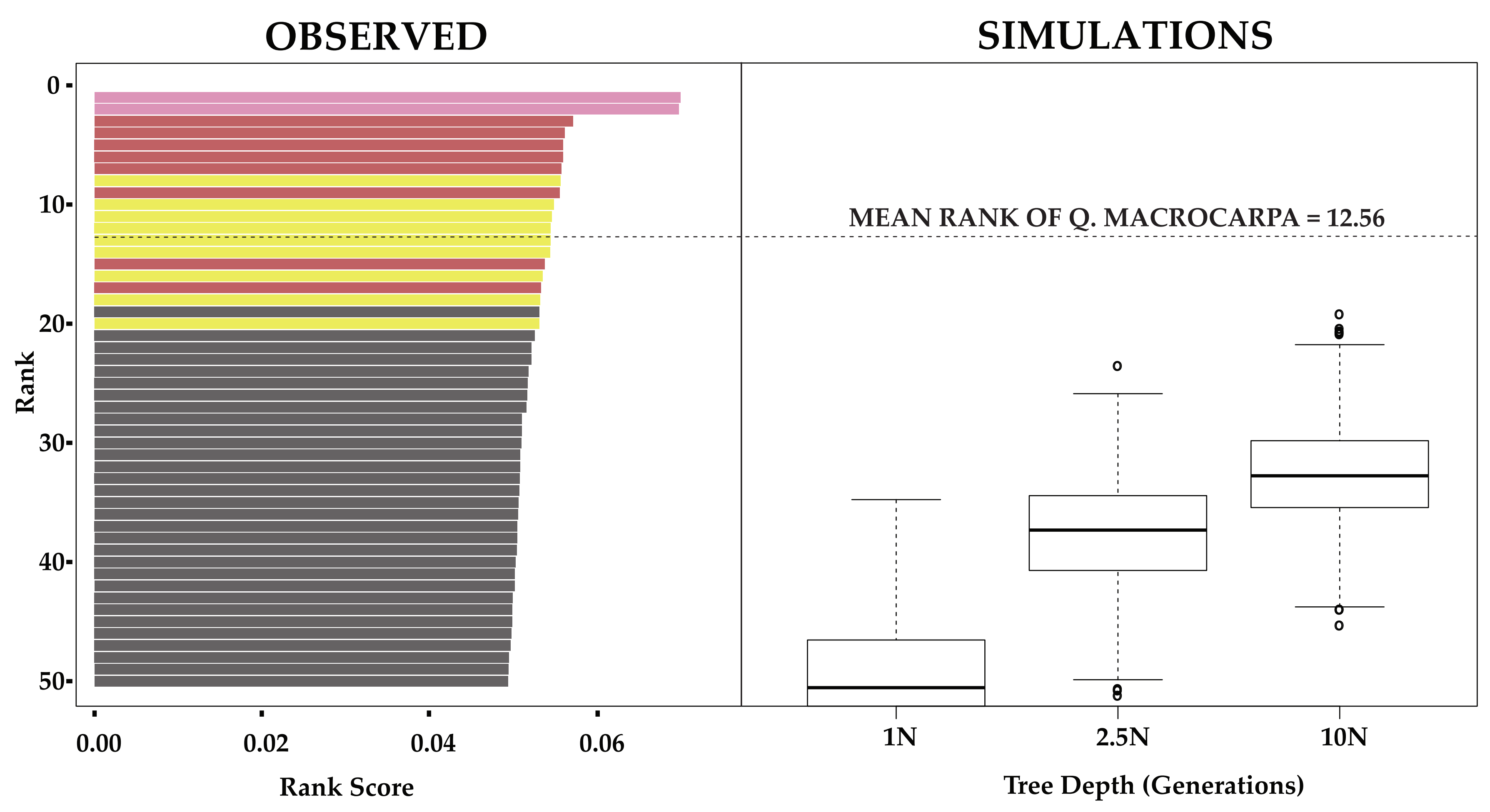

D. Q. macrocarpa - Q. michauxii OBSERVED SIMULATIONS

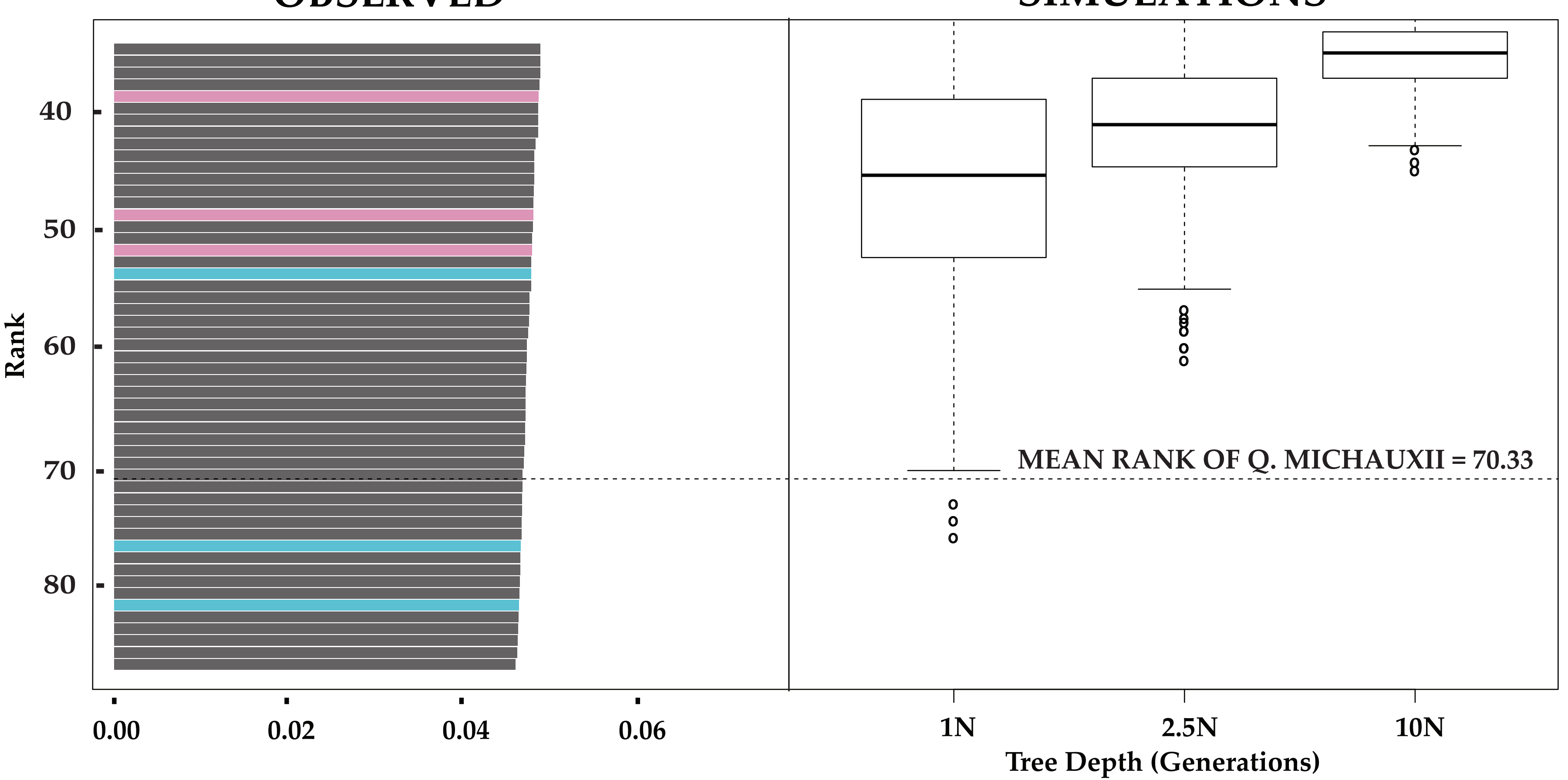

$\square$ Q. gambelii $\square$ Q. lobata $\square$ Q. macrocarpa $\square$ Q. michauxii $\square$ Other


A

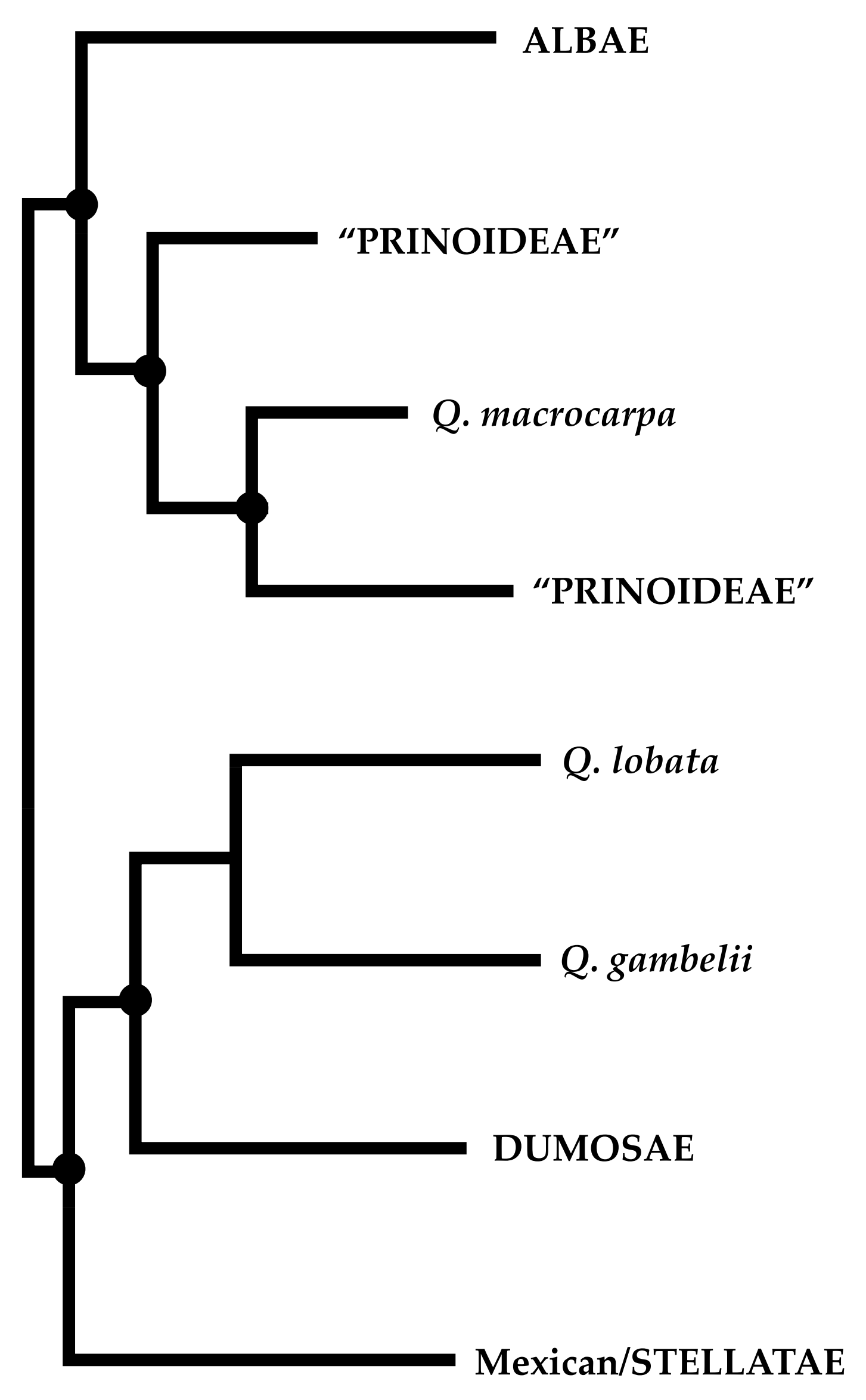

No “Q. gambelii + Q. macrocarpa"
B

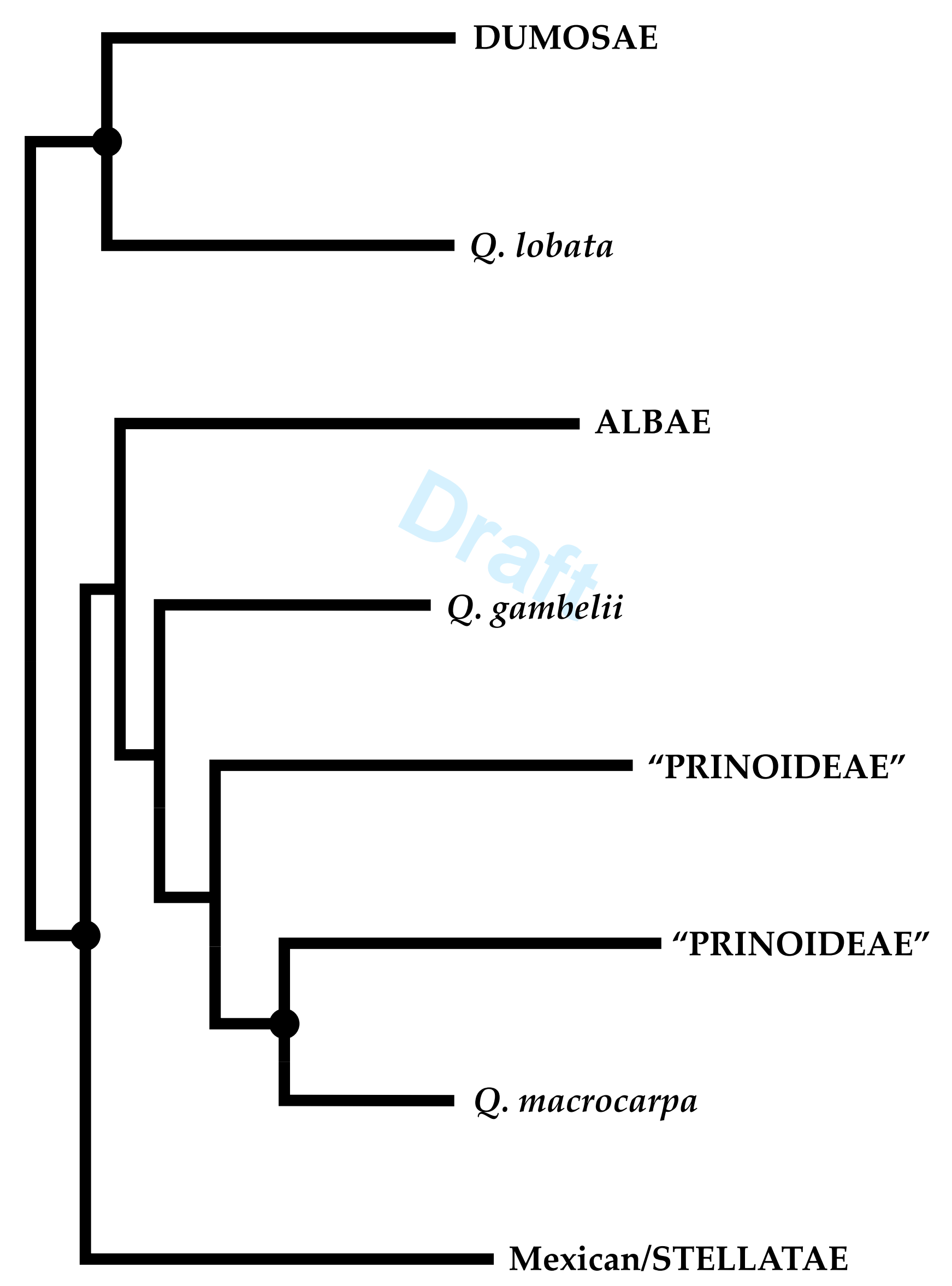

No "Q. gambelii + Q. lobata"
C

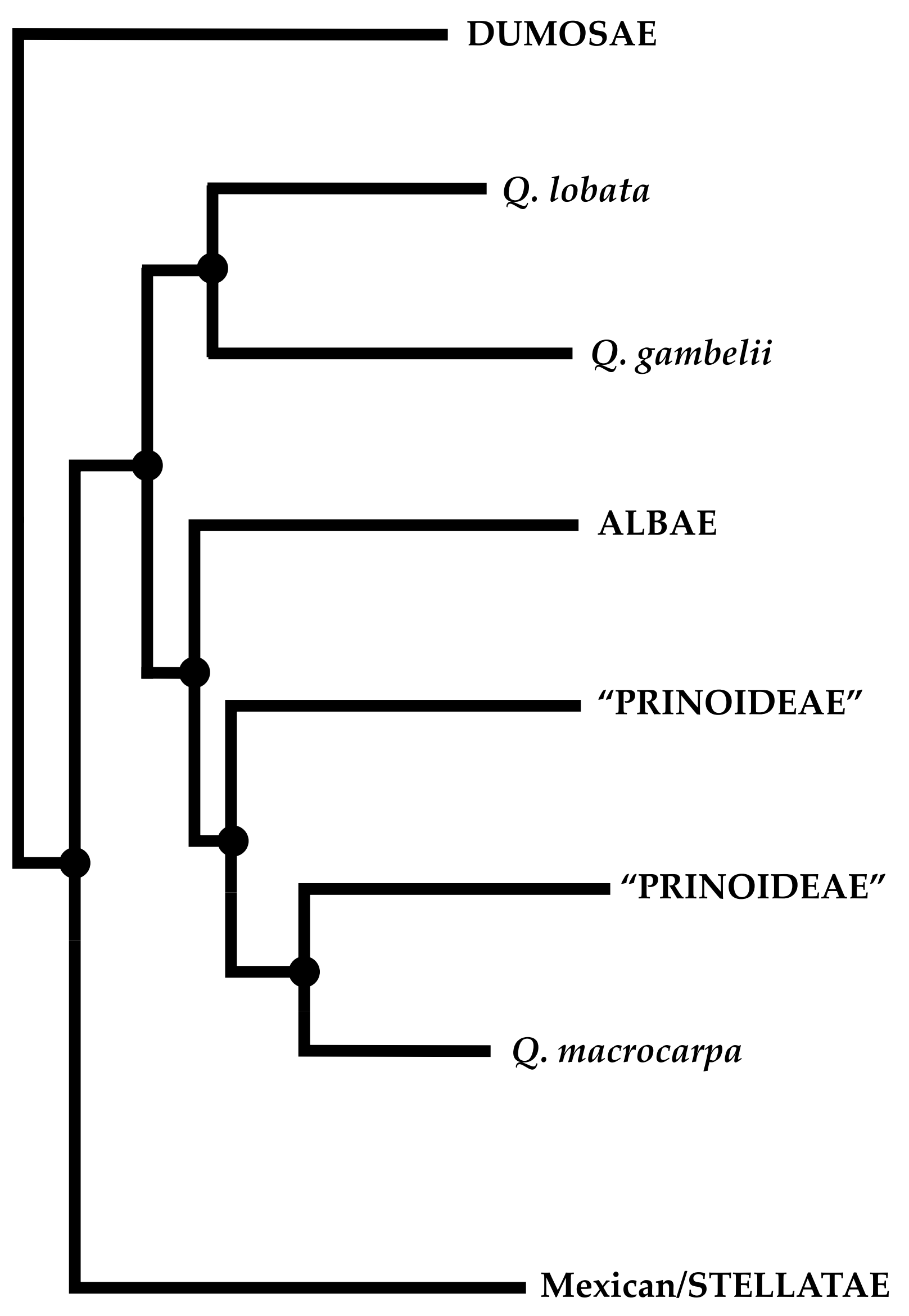

Unconstrained 


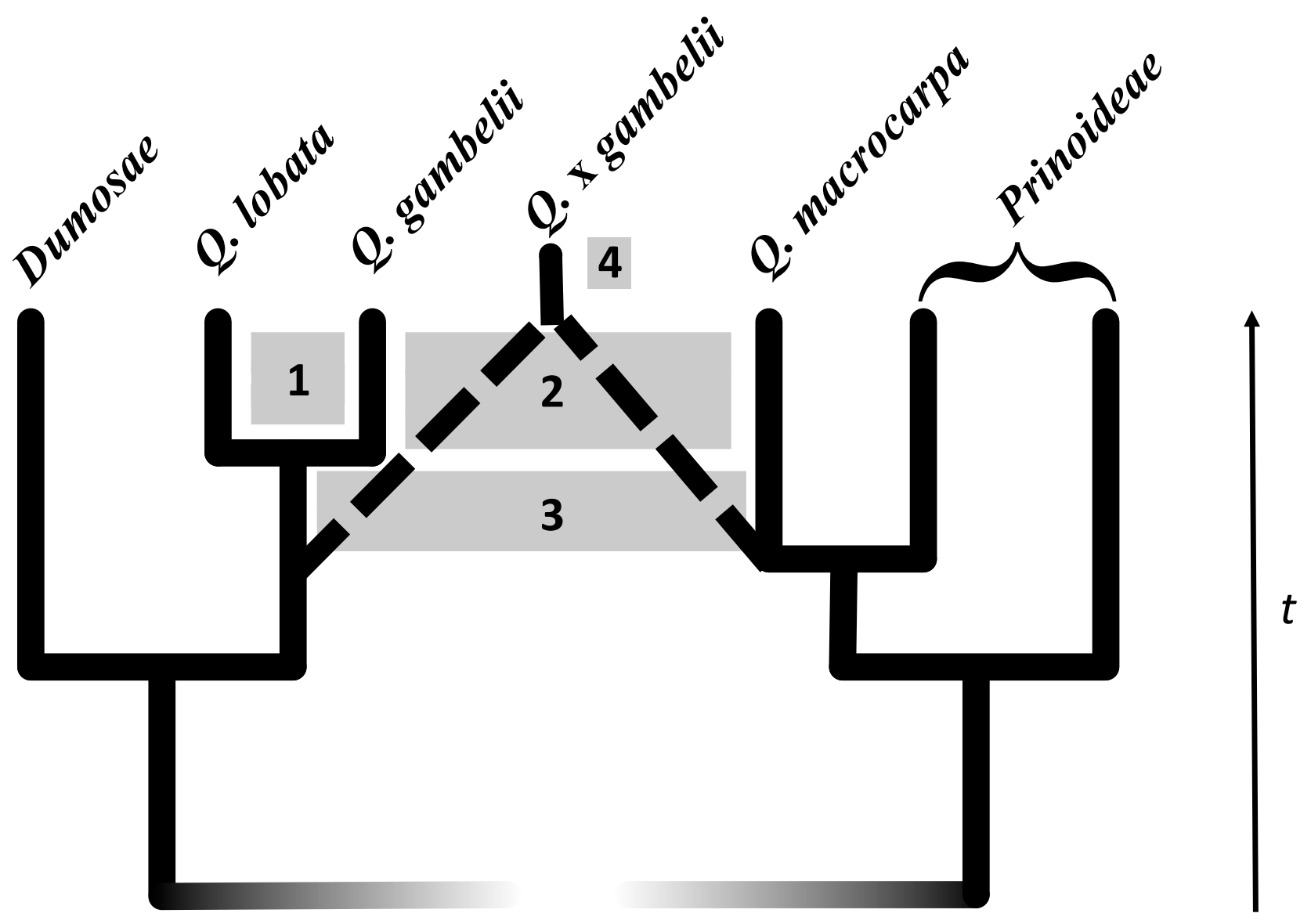

